\title{
A Research on the Performance Evaluation of University Students' Entrepreneurial Mentors
}

\author{
Liping Chen ${ }^{1, a}$ \\ ${ }^{1}$ School of Management, Wuhan University of Technology, Wuhan, P.R.China, 430070 \\ a15527972608@163.com
}

Keywords: Entrepreneurial mentor; University students 'innovative undertaking; Performance Evaluation

\begin{abstract}
Entrepreneurial mentors can provide university students entrepreneurs with entrepreneurial guidance and have an important role in improving the success rate of startups. However, because factors including the content, the form and the period of guidance are complex, how to evaluate the effective performance of the entrepreneurial mentor is an important issue. Based on the literature induction, combined with the characteristics of the entrepreneurial mentor's guidance, this paper puts forward the performance evaluation index system which based on the input-output conceptual model. It provides a solution to evaluate the entrepreneurial mentor effectively and comprehensively, and provides the basis for the entrepreneurial mentor management institutions to manage the entrepreneurial mentor.
\end{abstract}

\section{Introduction}

Entrepreneurial instructors can provide college students with various aspects of entrepreneurial practice guidance, and it is helpful to cultivate college students entrepreneurial awareness and entrepreneurial spirit. The performance evaluation of the entrepreneurial mentor can not only improve the quality of guidance and improve the success rate of college students, but also enhance the incubation ability of incubators such as Pioneer Park and improve the implementation effect of entrepreneurship education. However, the entrepreneurial mentor system at this stage is imperfect, because the mentor groups is huge, the guidance cycle is long and the influencing factors are complex, there are still many problems. For example, the guidance effect is difficult to measure (Liufeng et al., 2016), there is no special management mechanism, there is no effective entrepreneurial instructor performance evaluation system, entrepreneurial mentor lack of effective management, so it can not form a long-term and effective win-win situation (Lijuan, 2011). At present, foreign scholars' research about the guidance of entrepreneurial mentors mainly focuses on the influencing factors, and rarely involves the performance evaluation research(St-Jean and Audet, 2009). And the domestic research on the performance evaluation of the entrepreneurial mentor is also less, the evaluation index is single. In this context, in order to ensure the effective operation of the entrepreneurial mentor system and improve the quality of the entrepreneurial instructors guidance, it is necessary to conduct the research on the performance evaluation.

Therefore, the purpose of this study is to establish a reasonable performance appraisal index system for university students' entrepreneurial mentors. On the one hand, it is conducive to the establishment of scientific reward and punishment mechanism, reasonable and fair distribution of entrepreneurial performance, and establish more stable relationship between college students entrepreneurial team and entrepreneurial mentor. On the other hand, it is conducive to the formation of university students entrepreneurial mentor team that has a wealth of entrepreneurial experience and a strong sense of social responsibility, building a professional, normalized mentor mentoring mechanism.

\section{Literature review}

Performance is a result of an individual or organization that is implemented in a certain way within a certain time (Yangjie et al., 2016). Entrepreneurial mentor performance evaluation is a new 
application field of performance evaluation method. According to its characteristics, choosing the right performance evaluation method is the prerequisite for the evaluation. The definition of the entrepreneurial mentor is also improving over time. Sullivan (2000) argues that the entrepreneurial mentor is an experienced expert in helping and providing a new perspective to overcome the difficulties. Mullen (2006) describes the relationship as an experienced individual and an inexperienced individual which is the one-to-one relationship, this guidance will provide a series of developmental functions.

In the aspect of entrepreneurial mentor performance evaluation method, because the guidance effect of the entrepreneurial mentor is difficult to measure and the factors involved are complicated, the research on the entrepreneurial mentor abroad is hardly involved in the performance evaluation research, and the domestic scholars have two dimensions in this research. First, from the entrepreneurial mentor and its guiding effect. Chen Hongyuan (2014) argues that the evaluation of the guidance effect of the entrepreneurial mentor should increase the evaluation weight of the practical guidance, the youth entrepreneurial achievement and the guidance of the instructor's transformation in the traditional theoretical guidance; Chen Cheng (2015) pointed out that the evaluation of the mentor should not only consider the quality of its guidance evaluation, but also consider the evaluation of its guidance process. Second, from the perspective of entrepreneurial mentor guidance effect recognition. Liu Feng et al. (2015) find out the measurement tools used to evaluate and measure the guidance of entrepreneurial mentors from the perspective of entrepreneurial youth, and construct the entrepreneurial mentor's behavioral identity model by exploring and answering the formation process of the entrepreneurial mentor's behavior recognition Evaluation of Process - oriented Entrepreneurial Guidance.

In the research of the construction of the performance evaluation index system of the entrepreneurial mentor, the domestic scholars' research on the index is divided into two aspects. First, from the perspective of the quality of their own mentor, including the mentor's quality, psychological quality, cultural quality, ability and quality, practical skills, social services, effective communication, guidance skills and other aspects (Zhou yingying, 2015;Jia jianfeng, 2010). Second, from the perspective of guide performance of entrepreneurial mentor, including entrepreneurial mentors to guide the entrepreneurial situation, entrepreneurial success rate, stability of the operating rate, entrepreneurship to promote employment, guide students to start the business, entrepreneurial mentor to participate in entrepreneurial work and so on (Zhou yingying, 2015).

Entrepreneurial instructor performance evaluation is not only a new application field of performance evaluation method, but also has great significance for improving the quality of guidance of entrepreneurial mentors. However, the research of foreign scholars in the guidance of entrepreneurial instructors mainly focuses on the influencing factors, and rarely involves the research of performance evaluation, which the main reason is that the performance is difficult to measure (St-Jean and Audet, 2009). There are also few studies on the performance evaluation of entrepreneurial instructors in China. In the aspect of the research on the dimensionality of the performance evaluation method about the entrepreneurial mentor, the scholars' research contents are rich, but mostly remain in the development proposal of the performance evaluation of the entrepreneurial mentor, and do not carry on the concrete evaluation content practice. In the construction of the performance evaluation index of the entrepreneurial mentor, the content of the evaluation index has been rich, but it has not formed the system, and the evaluation angle is single and no systematic evaluation has been made.

\section{Constructing the Performance Evaluation Index System of University Students' Entrepreneurial Mentors}

Because of the constraints of time, content and form and other factors, the guide performance of entrepreneurial mentors is complex, it is difficult to simply measure. Furthermore, entrepreneurial mentor guidance is a long process, simple performance evaluation can not represent the entire guide effect. Do not take into account the whole process of mentoring mentor, but only through the error of the results to evaluate the quality of the entire guide, often with limitations, easily lead to 
mistakes, it is unfair performance for entrepreneurs and mentors.

This paper based on the analysis of influencing factors that performance of the guidance effect of domestic and foreign entrepreneurship mentors, also considers the characteristics of performance evaluation of entrepreneurial mentors, and the indicators that can be used to guide the performance evaluation of entrepreneurial mentors are divided into the three parts according to the input-out model, that is, entrepreneurial mentor resource input, entrepreneurial mentor guidance process and the results of entrepreneurial mentor guidance performance, to build a university student entrepreneurial mentor performance evaluation system.

The Evaluation of Entrepreneur Mentor Resource Input. According to the characteristics of university students' entrepreneurial mentor and university students' entrepreneurship, the evaluation of resource input of university students' entrepreneurship mentor includes four aspects: the richness of knowledge, the degree of coherence, the amount of time and the degree of input of instruction.

As the main body of entrepreneurship education, entrepreneurship mentor should have a solid professional knowledge, academic attainments, entrepreneurial experience, a wealth of experience in the entrepreneurial management and so on. The more knowledge and experience the entrepreneurial mentor has, the more helpful it will be for entrepreneurs in the process of guidance (Deakins et al., 1998).

The matching degree between the entrepreneurial mentor and the entrepreneur has a crucial role in improving the performance of tacit knowledge transfer. In the process of entrepreneurship, the choice of appropriate the main body and the receptor in tacit knowledge transfer, not only will enhance the performance of knowledge transfer, but also to promote entrepreneurs to accept the hidden knowledge of the integration of absorption and innovation, and thus improve business success rate (Liwei and Guo dongqiang, 2017).

The difference in time investment directly reflects the degree of attention given to the entrepreneurial mentor. The level of contact is closely related to the perception of the entrepreneurial behavior, and if the number of contacts is increased, the degree of awareness of the entrepreneurial behavior will be increased (Waters L, et al. 2002). The difference in the way and the degree of participation of the mentor directly affects the harvest of the entrepreneur from the guidance. Studies have shown that the combination of low direct and high participation is a better model (Cull, 2006).

Guidance content is the intuitive performance of the guidance of entrepreneurial mentor. The measure of entrepreneur mentor guidance content is mainly from the career-related and psychological counseling, the main measure is their respective investment proportion. Career guidance is a pioneering mentor to analyze the environment for entrepreneurs and provide developmental advice, so as to avoid the future difficulties of entrepreneurs, and psychological counseling is to provide opportunities for entrepreneurs to talk, triggering entrepreneurs to reflect on the current situation, to make it develop better (Cope and Watts, 2000).

The Evaluation of Entrepreneur Mentor Guidance Process. Entrepreneurship mentor guidance process evaluation is in the process of guiding behavior in the ongoing supervision and feedback, by describing the actual behavior to determine or identify the problems and shortcomings. According to the characteristics of the guidance of the entrepreneurial mentor, this part includes two aspects of the indicators, that is, guidance content feedback and entrepreneurial feedback on entrepreneurial mentor guidance.

Guidance content feedback is to assess the objective aspects of the guidance behavior in the course of the guidance of entrepreneurial mentor effect. The degree of instructional feedback is measured from three aspects: career guidance, psychological counseling, and role model, that is, whether the entrepreneur perceived the experience, technology and social information resources, whether it helps the entrepreneur's psychological construction and psychological toughness to strengthen, whether triggering the entrepreneur's imitation(St-Jean, 2011).

The entrepreneur feedback refers to the entrepreneur's perception of the guiding behavior from the subjective aspect. The degree of trust, the degree of trust, the degree of participation which between entrepreneurs and entrepreneurial mentor indirectly affect the guidance effect of the 
entrepreneurial mentor, that is, whether the entrepreneur agrees with the guidance of the entrepreneurial mentor, whether the entrepreneur is trust with the entrepreneurial mentor, whether the entrepreneur actively participate in the course of this guidance (St-Jean, 2009).

The Evaluation of Entrepreneur Mentor Guidance Performance. The guidance effect evaluation is an intuitive evaluation of the performance level achieved by the guidance of the entrepreneurial mentor, that is, based on the guidance of the entrepreneurial guidance behavior to measure and determine the degree which the guidance goal is achieved. Based on the characteristics of entrepreneurial mentors, it mainly refers to the performance evaluation of entrepreneurial enterprises.

The level of business performance is the analysis of the performance through entrepreneurial guidance from the objective data. Enterprise performance level is the most direct performance of entrepreneurial guidance, mainly including the growth in sales, market size, financing level and profitability which in the new business growth process through the guidance of entrepreneurial mentor(Bisk, 2002; Waters, et al. 2002).

Table 1 Performance Evaluation Index of College Entrepreneurs Mentors

\begin{tabular}{|c|c|c|}
\hline Level 1 indicators & Level 2 indicators & Level 3 indicators \\
\hline \multirow{10}{*}{$\begin{array}{l}\text { Performance Evaluation Index } \\
\text { of College Entrepreneurs } \\
\text { Mentors }\end{array}$} & \multirow{4}{*}{$\begin{array}{l}\text { The evaluation of entrepreneur } \\
\text { mentor resource input }\end{array}$} & the richness of knowledge \\
\hline & & the degree of coherence \\
\hline & & the amount of time \\
\hline & & $\begin{array}{l}\text { the degree of input of } \\
\text { instruction }\end{array}$ \\
\hline & \multirow[t]{2}{*}{$\begin{array}{l}\text { The evaluation of entrepreneur } \\
\text { mentor guidance process }\end{array}$} & $\begin{array}{l}\text { guidance content feedback on } \\
\text { entrepreneurial } \\
\text { guidance }\end{array}$ \\
\hline & & $\begin{array}{lr}\text { entrepreneurial } & \text { feedback on } \\
\text { entrepreneurial } & \text { mentor } \\
\text { guidance } & \end{array}$ \\
\hline & \multirow{4}{*}{$\begin{array}{l}\text { The evaluation of entrepreneur } \\
\text { mentor guidance performance }\end{array}$} & Sales growth \\
\hline & & Market size growth rate \\
\hline & & Raising the level of financing \\
\hline & & Increased profitability \\
\hline
\end{tabular}

\section{Conclusion}

In recent years, with the prevalence of entrepreneurial activities, entrepreneurship education and various incubators are also evolving, the number of entrepreneurial tutor is increasing. However, the entrepreneurial mentor system at this stage is imperfect, because the mentor groups is huge, the guidance cycle is long and the influencing factors are complex, there are still many problems. In this context, in order to ensure the effective operation of the entrepreneurial mentor system and improve the quality of the entrepreneurial instructors guidance, it is necessary to conduct the research on the performance evaluation.

At present, domestic and foreign scholars have less research on the performance evaluation of entrepreneurial mentor, the angle is single, and the performance is rarely analyzed from the whole process of guiding process. This paper through the literature induction method, taking into account a variety of factors, build an evaluation system that from the input - output process point of the entrepreneurial mentor guidance. This paper hopes to enrich the performance evaluation content and the performance evaluation research of entrepreneurial mentor, and can apply it to the actual performance of the entrepreneurial mentor performance evaluation, to promote the further improvement of the entrepreneurial mentor system. 


\section{Acknowledgements}

This research was financially supported by" the Fundamental Research Funds for the Central Universities" (175203007).

\section{References}

[1] LiuFeng, Xiong Xiaofei, ChenGuang. A Research on foreign entrepreneurship mentor: retrospect, review and expectation[J]. Science of Science and Management of S.\& T., 2016, 37(8):47-57 (In Chinese)

[2] St-Jean E, Audet J. The role of mentoring in the learning development of the novice entrepreneur[J]. International Entrepreneurship \& Management Journal, 2009, 8(1):119-140.

[3] Sullivan R. Entrepreneurial learning and mentoring[J]. International Journal of Entrepreneurial Behaviour \& Research, 2000, 6(3):160-175

[4] Mullen E J. Vocational and psychosocial mentoring functions: Identifying mentors who serve both[J]. Human Resource Development Quarterly, 2006, 9(4):319-331

[5] ChenCheng. A Research on the influencing factors and the mechanism of Enterprise mentor 's Guiding Behavior[D]. Huazhong University Of Science And Technology, 2013 (In Chinese)

[6] LiuFeng, Song Xiaoting, Wei Yifei. Entrepreneurship mentor Guiding Behavior Formation Mechanism[J]. Studies in Science of Science, 2015, 33(8):1225-1231 (In Chinese)

[7] Deakins D, Graham L, Sullivan R, et al. New venture support: an analysis of mentoring support for new and early stage entrepreneurs[J]. Journal of Small Business and Enterprise Development, 1998, 5(2):151-161(11)

[8] LiWei, Guo Dongqiang. A Study on the Evaluation Mechanism of Recessive Knowledge Transfer in Enterprise[J]. Information studies:Theory \& Application, 2017(2):102-106 (In Chinese)

[9] Waters L, Mccabe M, Kiellerup D, et al. The Role of Formal Mentoring on Business Success and Self-Esteem in Participants of a New Business Start-Up Program[J]. Journal of Business and Psychology, 2002, 17(1):107-121

[10] Cull J. Mentoring Young Entrepreneurs: What Leads to Success?[J]. International Journal of Evidence Based Coaching \& Mentoring, 2006(2):8-18

[11] Cope J, Watts G. Learning by doing-An exploration of experience, critical incidents and reflection in entrepreneurial learning[J]. International Journal of Entrepreneurial Behavior \& Research, 2000, 6(3): 104-124

[12] St-Jean E. Mentor functions for novice entrepreneurs[J]. Academy of Entrepreneurship Journal, 2011, 17(1): 65

[13] St-Jean E. Factors Leading to Satisfaction in a Mentoring Scheme for Novice Entrepreneurs[J]. International Journal of Evidence Based Coaching \& Mentoring, 2009

[14] Bisk L. Formal entrepreneurial mentoring: the efficacy of third party managed programs[J]. Career Development International, 2002, 7(5):262 - 270

[15] Waters L, Mccabe M, Kiellerup D, et al. The Role of Formal Mentoring on Business Success and Self-Esteem in Participants of a New Business Start-Up Program[J]. Journal of Business and Psychology, 2002, 17(1):107-121 